\title{
A comparative study on digit ratio and hand patterns of three ethnic races of Malaysia
}

\author{
Satheesha B. Nayak, Dhiviah Nair ${ }^{1,2}$, Vimal Ravi ${ }^{1,2}$ and Ashwini P. Aithal ${ }^{1 *}$
}

\begin{abstract}
Background: To distinguish the characteristic hand pattern of each of the three different ethnicities in Malaysia and to study the hand pattern correlation between race and gender.

Method: Individual lengths of the fingers were then measured and tabulated to serve as the basis for analyzing the 2D (second digit):4D (fourth digit) hand ratio. Based on this ration, the hand patterns were classified as A, B, and C types.

Results: Hand pattern A (2D<4D) appears to be the most characteristic trait in Malays. The highest scoring hand pattern in Chinese is A as well with scores of $52 \%$ in their right hands and $60 \%$ in their left hands. In Indians, hand pattern C (2D $>4 D)$ shows dominance in their right hands with a score of $46 \%$ while hand pattern $A$ dominates their left hands. Among the males, all three races show dominance in hand pattern A except in Chinese whereby the C hand pattern was dominant in their right hands (44\%). Among the females, the most common trait in Malays and Chinese are the hand pattern $A$ in both their hands. Indian females, however, showed dominance in hand pattern $C$ in their right hands $(60 \%)$, and hand pattern B $(2 \mathrm{D}=4 \mathrm{D})$ dominated in their left hands $(44 \%)$. Results of the statistical analysis revealed that there was a highly significant difference in the hand patterns of both the hands when compared to gender.

Conclusion: The study suggests that ratio below or equal to 0.90 is suggestive of female sex for both hands, while a ratio of more than 0.91 is suggestive of male sex for both hands. The pattern $A(2 D<4 D)$ is seen to be the most common trait among the three ethnicities of Malaysia with an exception seen in the right hands of Indians.
\end{abstract}

Keywords: Hand pattern, Digit ratio, Malaysians, Race, Correlation

\section{Background}

The morphological and anthropometric relationship that exists between different parts of the body and sex of an individual has been of great interest to forensic experts, anthropologists, and medical scientist for a long time. Hand pattern refers to the outline of the palm and fingers in the adducted position. In prior researches on hand patterns and digit ratios, it has been concluded that the two most significant contributing factors to this pattern are the gender and the race of a person. Digit ratio is the ratio of the length of different digits or fingers typically measured from the bottom crease where the fingers join the hands to the

\footnotetext{
* Correspondence: ashwini.anat@gmail.com

'Department of Anatomy, Melaka Manipal Medical College (Manipal campus), Manipal Academy of Higher Education, Manipal 576104, Karnataka, India

Full list of author information is available at the end of the article
}

tip of the fingers. However, most commonly, digit ratios indicate only 2D (index finger):4D (ring finger) ratios as this ratio has been shown to be sensitive and interlinked with health hazards and human traits (Mayhew et al. 2007). In humans, the second finger to the fourth finger (2D:4D) ratio is sexually dimorphic (Manning 2008). Sex difference on 2D:4D is generally fixed in utero (Malas et al. 2006; Galis et al. 2010) and then present in newborns (Ventura et al. 2013). Individual 2D:4D ratio remains relatively stable over the lifespan. The ratio of 2D:4D has been shown to be directly related to various human phenotypic traits like special abilities, numerical, spatial, and behavioral skills (Luxen and Buunk 2005). Studies have reported variations in digit ratios among different ethnic and geographic groups. The ratios are said to vary owing to the individual variance in height, gender, ethnicity, and genetic influence. Study on the index 


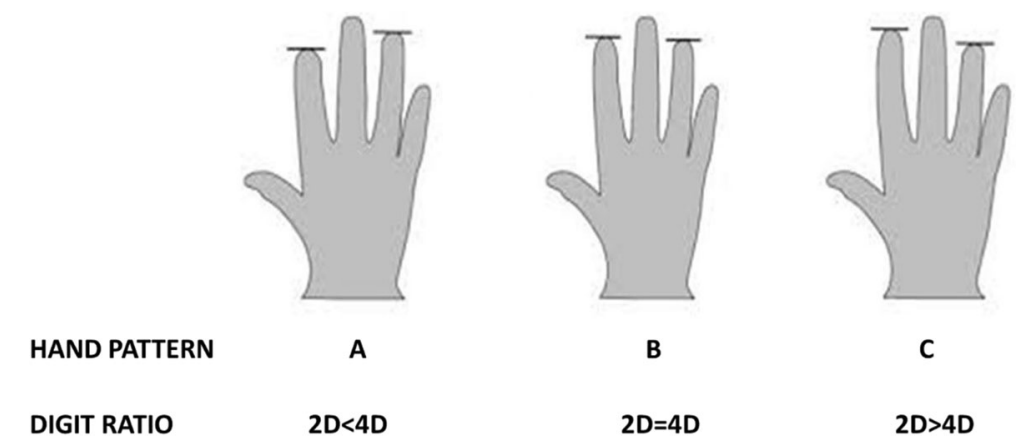

Fig. 1 Figure shows the classification of hand patterns based on digit ratio. Hand pattern a $(2 D<4 D)$; Hand pattern $\mathbf{b}(2 D=4 D)$; Hand pattern $\mathbf{c}(2 D>4 D)$

and ring finger ratio is also crucial in terms of its legal significance. Variations in the digit ratio and hand patterns between populations can be utilized well in forensic casework in cases of mass disasters whereby it is impossible to identify their physical features. It is here that accurate sexing of the human remains is essential. Digit ratios and hand pattern analysis have the potential to narrow down the search to particular sex thus giving a sense of direction to the forensic investigation.

During our literature review, we found that there is limited data on population-based studies on the correlation of digit ratios. Owing to its importance in health and other factors as stated above, there is a need for regional studies on digit ratios as the human species exhibit a lot of racial and ethnic variations. Hence, the present study was undertaken to compare the digit ratios and hand patterns between the three ethnic races of Malaysia.

\section{Objectives}

The principal objective of this study was to compare the digit ratio among the participants belonging to three ethnic races of Malaysia. The second objective was to group the obtained hand patterns into three types based on the digit ratio. The third objective was to observe if there are any race-wise and gender-wise correlations in hand patterns and digit ratio among the studied Malaysian races.

\section{Methodology}

\section{Participants}

The study was a cross-sectional type involving 150 participants (75 males and 75 females). These participants were undergraduate medical students, and their participation was purely on a voluntary basis. The students belonged to three different Malaysian ethnic races, i.e., Malays, Chinese, and Indians (Malaysian Indians). The study was done after obtaining ethical clearance from the institutional ethics committee (IEC No: 348/2016). Students of Malaysian nationality and those with distinctive bloodlines were included in this study as those of mixed blood may contribute to certain deviations in the hand patterns. Students with damaged/injured fingers, scars, or inflammation or with congenital anomalies of the hand and students with parents of different ethnicities (mixed blood) were excluded from this study.

\section{Materials}

Questionnaires were used in the present study which was validated by academic faculty. The questionnaire included the student's demographic data.

\section{Procedure for data collection}

Right- and left-hand tracing of the individual students was obtained by asking the participants to keep the hand flat on the plain side of the questionnaire paper, keeping the fingers together and thumb lying comfortably against the radial aspect of the index finger. A tracing was made using a pencil. The tracing started from the tip of the radial styloid process, passing all around the fingers, and the hand ended at the tip of the ulnar styloid process. The investigators of this study guided the hand tracing process. The measurements were taken uniformly by the investigators in the same way and under the same

Table 1 Table showing the percentage distribution of hand patterns among the three races based on gender

\begin{tabular}{|c|c|c|c|c|c|c|c|c|c|c|c|c|}
\hline & \multicolumn{6}{|c|}{ Hand pattern (right hand) } & \multicolumn{6}{|c|}{ Hand pattern (left hand) } \\
\hline & \multicolumn{3}{|c|}{ Male $(n=75)$} & \multicolumn{3}{|c|}{ Female $(n=75)$} & \multicolumn{3}{|c|}{ Male $(n=75)$} & \multicolumn{3}{|c|}{ Female $(n=75)$} \\
\hline & $\bar{A}$ & $B$ & c & $\bar{A}$ & $B$ & c & A & B & c & A & B & c \\
\hline Malay & $60 \%$ & $32 \%$ & $8 \%$ & $48 \%$ & $40 \%$ & $12 \%$ & $40 \%$ & $32 \%$ & $28 \%$ & $76 \%$ & $20 \%$ & $4 \%$ \\
\hline Chinese & $40 \%$ & $16 \%$ & $44 \%$ & $64 \%$ & $12 \%$ & $24 \%$ & $56 \%$ & $32 \%$ & $12 \%$ & $64 \%$ & $24 \%$ & $12 \%$ \\
\hline Malaysian Indians & $48 \%$ & $20 \%$ & $32 \%$ & $24 \%$ & $16 \%$ & $60 \%$ & $52 \%$ & $36 \%$ & $12 \%$ & $32 \%$ & $11 \%$ & $24 \%$ \\
\hline
\end{tabular}




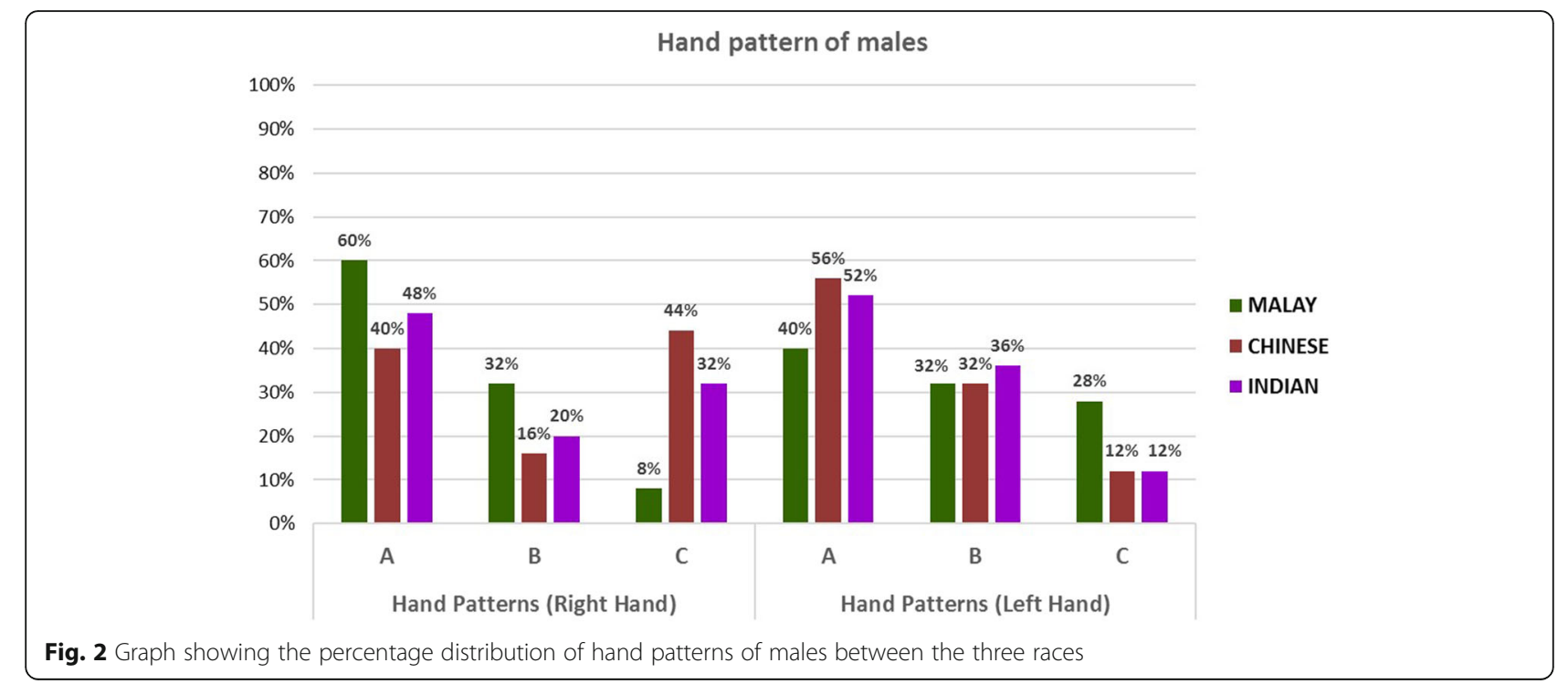

conditions to avoid inter-observer errors. The lengths of the second and fourth digits were determined using a direct method of measurement of Manning et al. 2010. The participants were asked to remove finger rings, and the lengths of the second and fourth digits were measured of both the right and left hands using a scale. The length of the fingers was measured from their proximal flexion creases up to the tip of the fingers, and the lengthwise relationship between the digits was calculated. The current method was most practical and therefore was considered appropriate. Every digit was measured twice, and the average was taken. The ratio between the second and fourth digit (2D:4D) was obtained by dividing the length of the second digit by the length of the fourth digit. The ratio values were calculated for the right and left side separately. Overall hand patterns were assessed and grouped.

\section{Data analysis}

All the data which was obtained was first segregated according to gender and then according to race. The hand patterns were classified into three patterns (A, B, and C) based on the 2D:4D ratio (Fig. 1) and analyzed. Appropriate charts and graphs were used to represent the results obtained. SPSS v 16.0 was employed for the statistical analysis of the research data. Descriptive statistics, i.e., mean and standard deviation for $2 \mathrm{D}$ and 4D digit length, was calculated. Male-female differences for the variables were observed using independent $t$ test. One-way ANOVA was used for comparison

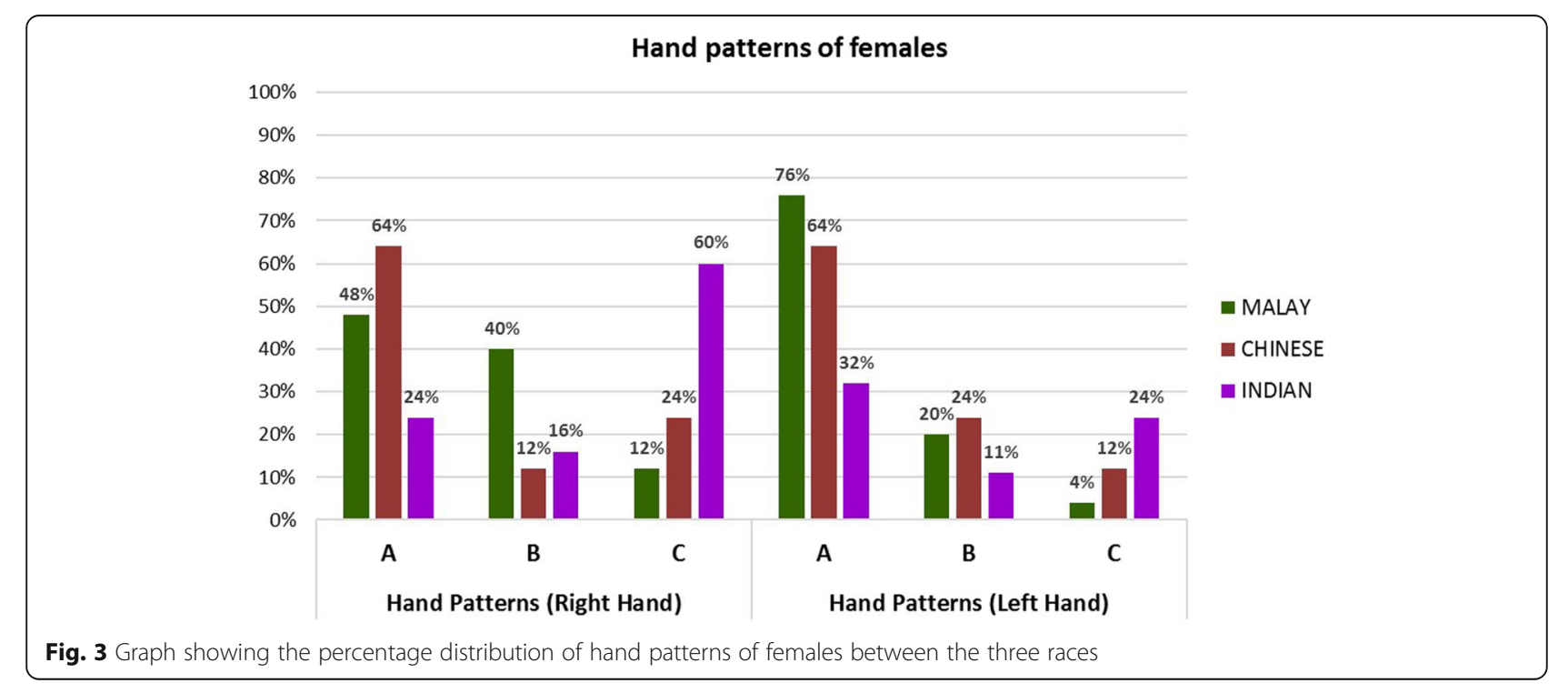




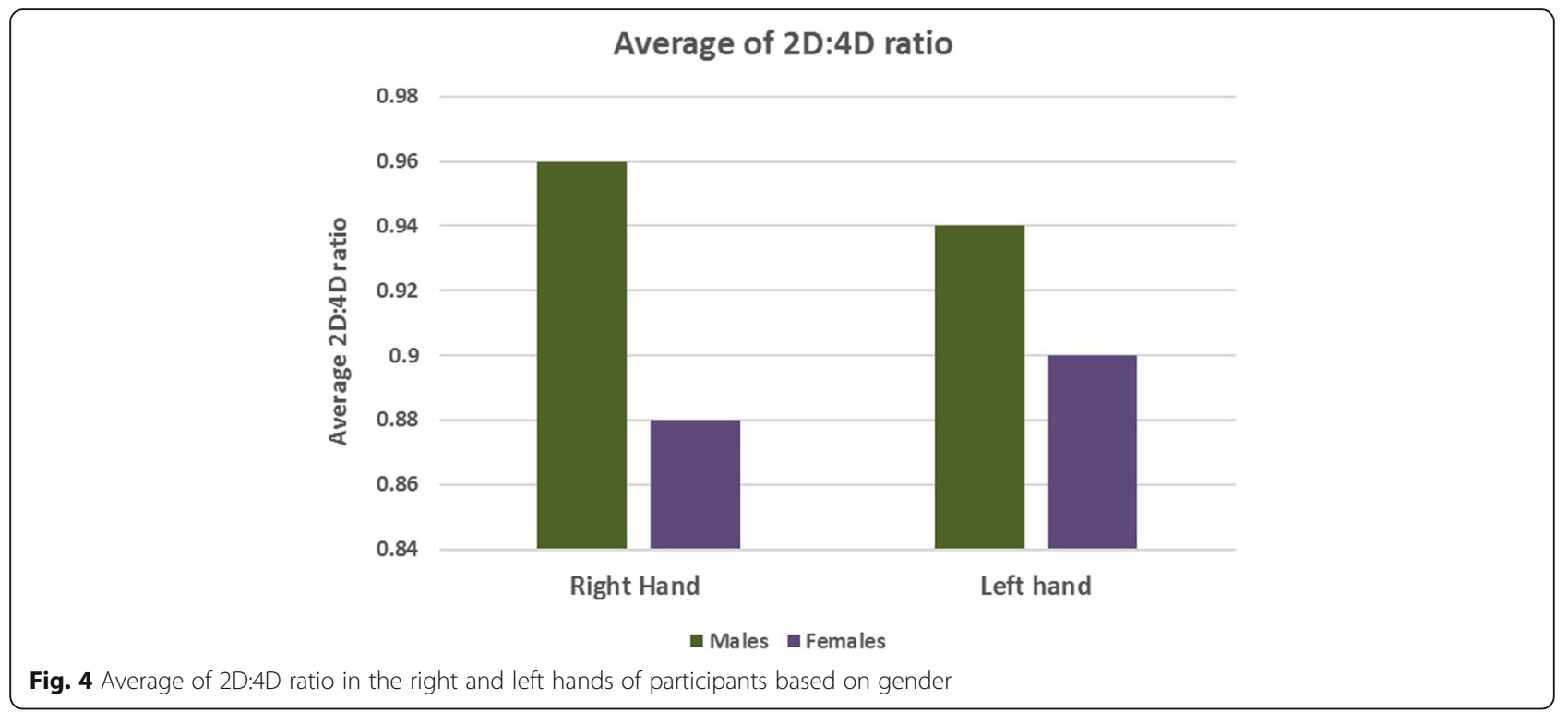

between the groups. $P<0.05$ was considered to be statistically significant.

\section{Results}

Hand pattern analysis revealed that the general pattern in most of the participants was pattern A $(2 \mathrm{D}<4 \mathrm{D})$. When the hand pattern was segregated based on races, it showed that, hand pattern A $(2 \mathrm{D}<4 \mathrm{D})$ appears to be the most characteristic trait in Malays seen in both their right and left hands with scores of $54 \%$ and $58 \%$, respectively. The standard pattern in Chinese was A as well with scores of $52 \%$ in their right hands and $60 \%$ in their left hands. In Indians, however, hand pattern $\mathrm{C}(2 \mathrm{D}>4 \mathrm{D})$ shows dominance in their right hands with a score of $46 \%$ while hand pattern A dominates their left hands with a score of $42 \%$ (Table 1). Statistical analysis showed that there was no significant difference between the right-hand pattern among the three races $(p=0.15)$. However, the difference was seen in the left-hand pattern among the races which was statistically significant $(p=0.007)$. When the hand patterns were analyzed based on gender, it indicated that pattern A dominated among the males in both their hands with similar scores of $49 \%$ each. Among the females, also hand pattern $\mathrm{A}$ appears to be the most common trait in both the right hands (45\%) and left hands (57\%). When the hand patterns were compared based on races and gender, among the males, all three races show dominance in hand pattern A except in Chinese males whereby the $\mathrm{C}$ hand pattern is the highest scoring group of their right hands (44\%) (Fig. 2).

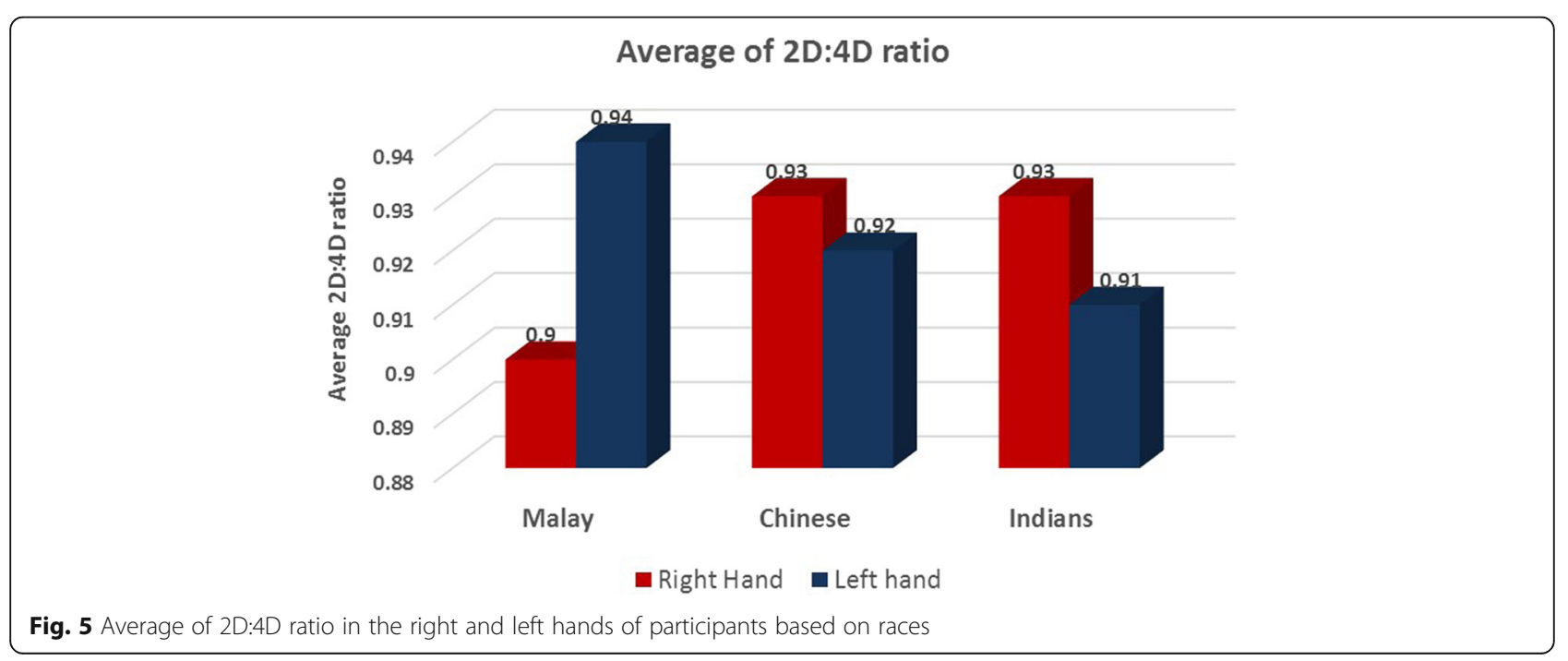




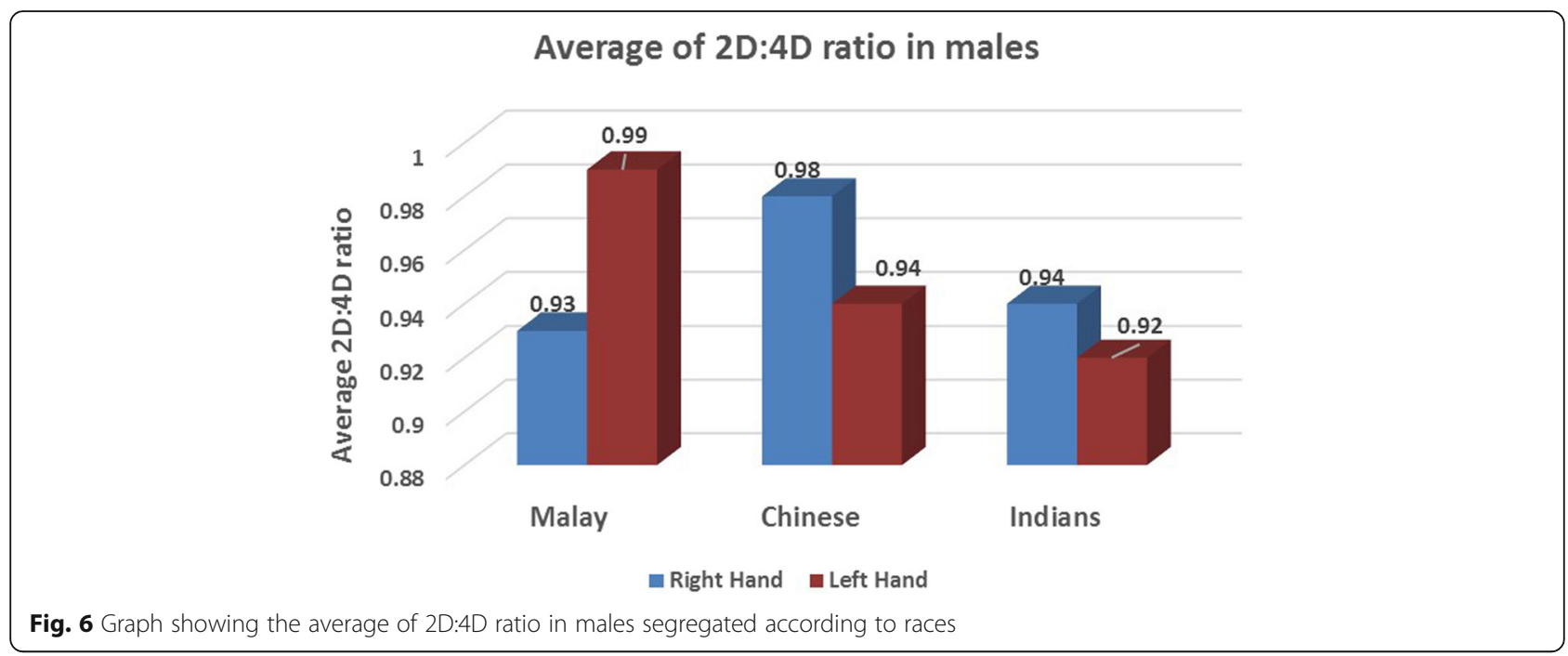

When comparing the hand patterns among the females, the most common trait in Malays and Chinese are the hand pattern $\mathrm{A}$ of both their hands. Indian females, however, showed dominance in hand pattern $\mathrm{C}$ in their right hands $(60 \%)$, and hand pattern $\mathrm{B}(2 \mathrm{D}=$ 4D) dominated the statistics in their left hands (44\%) (Fig. 3). Results of the statistical analysis revealed that there was a highly significant difference in the hand patterns of both the hands when compared to gender (right hand, $p=0.004$; left hand, $p=0.006$ ).

Analysis of 2D:4D digit ratios showed few variations among the races and when segregated according to gender. The average of 2D:4D ratio in males (right hand, 0.96; left hand, 0.94) was higher when compared to females (right hand, 0.88; left hand, 0.90) (Fig. 4). Statistical analysis using $t$ test revealed significant differences in the digit ratios between males and females (right hand, $p<0.05$; left hand, $p<$ $0.05)$. However, there was no correlation between the digit ratios of both the hands compared to gender $(r=0.17)$. When the average digit ratio was grouped according to race, we found that in the right hand, the average ratio was higher in Chinese and Indians (0.93), while in the left hand, the average ratio was higher in Malay (0.94) (Fig. 5). When these ratios were further analyzed based on gender, it was found that in males, the average digit ratio of the right hand was higher in Chinese (0.98) and of the left hand, it was higher in Malay (0.99) (Fig. 6). In females, the average digit ratio of the right hand was higher in Chinese (0.89), and of the left hand, it was higher in Chinese and Indians (0.90) (Table 2, Fig. 7).

\section{Discussion}

Hand analysis has fascinated researchers throughout history. In recent times, two aspects of the human hand have drawn attention for observation and analysis including dermatoglyphic ridge pattern and, secondly, finger lengths and their ratios. The present study is unique as for the first time, it presents information on 2D:4D and hand patterns of both sexes in students of Malaysian ethnicity. Digit ratio is sexually dimorphic and can be used as a window for in utero exposure to androgens, primarily testosterone (Jeevanandam and Muthu 2016). However, there is no harmony on the intra-sexual and inter-sexual variations in digit ratios and traits across various ethnic groups. The morphological gender difference reported is that male fingers are significantly longer as compared to female fingers (Williams et al. 2000; Lippa 2003). In females, the index and ring fingers are reported to be almost of equal length, while in males, the ring finger tends to be longer than the index finger. The 2D:4D ratio is lower in men as compared to women (Setiya et al. 2017). However, in our study, we observed that the ring finger was longer than the index finger in both males and females which indicates that the digit ratio varies depending on various populations and

Table 2 Mean \pm SD of 2D:4D digit ratio among the males and females of Malaysian ethnicity

\begin{tabular}{|c|c|c|c|c|}
\hline & \multicolumn{2}{|l|}{ Right hand } & \multicolumn{2}{|l|}{ Left hand } \\
\hline & Male $(n=75)$ & Female $(n=75)$ & Male $(n=70)$ & Female $(n=75)$ \\
\hline Malay & $0.93 \pm 0.06$ & $0.88 \pm 0.04$ & $0.99 \pm 0.09$ & $0.89 \pm 0.05$ \\
\hline Chinese & $0.98 \pm 0.09$ & $0.89 \pm 0.08$ & $0.94 \pm 0.07$ & $0.90 \pm 0.07$ \\
\hline Malaysian Indians & $0.94 \pm 0.12$ & $0.87 \pm 0.04$ & $0.92 \pm 0.07$ & $0.89 \pm 0.06$ \\
\hline
\end{tabular}




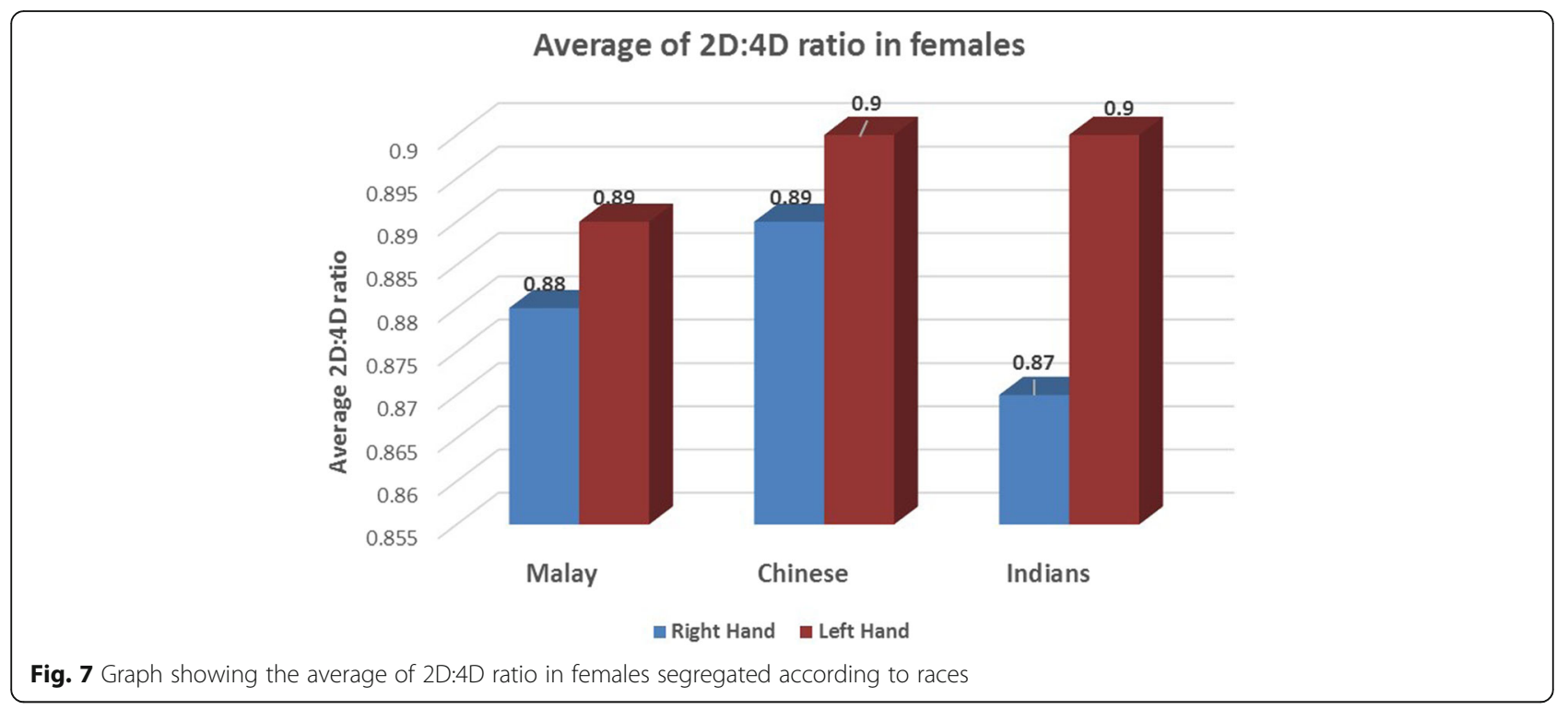

geographic distribution. Many studies have reported the existence of significant sex differences in 2D, 4D, and its ratio in different ethnic populations and its bilateral variations among individuals (Voracek et al. 2008; Krishan et al. 2013; Sen et al. 2014). Sex differences in the digit ratio can be a valuable indicator mainly when DNA analyses cannot be performed (Aboul-Hagag et al. 2011).

Results of the present study on hand patterns based on digit ratio indicated that hand pattern $A(2 D<4 D)$ was the most prevalent trait among Malaysians seen in both their right and left hands which indicates that no significant difference exists between the ethnic groups of Malaysia. Similar results have been obtained in previous studies involving different study populations such as China (Xu et al. 2015), Nigeria (Gwunireama and Ihemelandu 2010), Italy, and Romania (Tomulescu and Nicoras 2015). Thus, it is possible that significant differences are more likely to be observed when comparing races from different countries along different latitude than ethnic groups or tribal groups. In the view of such contradicting results, more studies are needed to verify this claim.

The available literature and data from recent research indicate accumulating evidence on 2D:4D ratio showing correlations with various phenotypic traits and health in humans. Males with higher digit ratio are said to be more prone to have low sperm counts, augmented the risk of heart disease, obesity, and metabolic syndrome (Oyeyemi et al. 2014). Higher digit ratios in males also showed a correlation with eating disorders, anxiety, and depression (Manning et al. 2013). Low digit ratio is linked with certain characteristics like aggression in males and assertiveness in females (Hampson and Sankar 2012). Martel et al. 2009 reported the male vulnerability to behavior disorders in children and female vulnerability to emotional disorders in adolescence. This evidence suggests the positive relationship between hand patterns and health. Hand patterns have also shown the potential to narrow down the search to particular sex and give the right direction to the ongoing forensic investigation. Studies have focused on the role of hand and foot measurements in establishing the biological profile of individuals in the forensic investigation (Kanchan et al. 2010; Kanchan and Krishan 2011). However, its utility is limited in forensic casework as it is shown to vary between different populations. Hence, the technique of measuring hand patterns might be beneficial in situations where no other means of sexing are available like in the case of war, natural calamities, in a bomb blast, and accidents (Dey and Kapoor 2016). Identification of sex of human remains can immensely help forensic experts while dealing with dismembered and fragmentary remains and in a criminal investigation by reducing the pool of possible victim matches (Dey and Kapoor 2016). Due to the dimensional diversity of the individual body, anthropological measurements of an individual may not be steadily credible tools for discrimination of sex. Therefore, determination of sex through indices like hand patterns and digit ratios can be additional credible tools in sexual dimorphism. In developing countries, this method of hand pattern estimation based on digit ratios can be highly useful for identification especially considering its cost-effectiveness.

Limitations of the study include small sample size, and the focus was only on the Malaysian population. More robust studies on large samples and between different nationalities can help establish meaningful associations between digit ratios and sexually dimorphic traits. This study included a comparison between participants of the same age groups. Hence, these findings cannot be compared with children or the elderly population. 


\section{Conclusion}

The study reveals that sexual dimorphism exists concerning digit ratio and can be significantly used to establish sexual dimorphism. The study suggests that ratio below or equal to 0.90 is suggestive of female sex for both hands, while a ratio of more than 0.91 is suggestive of male sex for both the hands. The pattern A $(2 \mathrm{D}<4 \mathrm{D})$ is seen to be the most common trait among the three ethnicities of Malaysia with an exception seen in the right hands of Indians.

\section{Authors' contributions \\ All persons listed as authors have contributed to preparing the manuscript and no person or persons other than the authors listed have contributed significantly to its preparation. All authors read and approved the final manuscript.}

\section{Ethics approval and consent to participate}

The study was performed after obtaining clearance from institutional ethics committee (IEC No: 348/2016) and written informed consent from the participants.

\section{Consent for publication}

All authors give their consent for publication.

\section{Competing interests}

The authors declare that they have no competing interests.

\section{Publisher's Note}

Springer Nature remains neutral with regard to jurisdictional claims in published maps and institutional affiliations.

\section{Author details}

${ }^{1}$ Department of Anatomy, Melaka Manipal Medical College (Manipal campus), Manipal Academy of Higher Education, Manipal 576104, Karnataka, India. ${ }^{2}$ Melaka Manipal Medical College (Manipal Campus), Manipal Academy of Higher Education, Manipal 576104, Karnataka, India.

Received: 1 May 2018 Accepted: 13 September 2018

Published online: 20 September 2018

\section{References}

Aboul-Hagag KE, Mohamed SA, Hilal MA, Mohamed EA (2011) Determination of sex from hand dimensions and index/ring finger length ratio in Upper Egyptians. Egypt J Forensic Sci 1:80-86

Dey S, Kapoor AK (2016) Digit ratio (2D:4D) - a forensic marker for sexual dimorphism in North Indian population. Egypt J Forensic Sci 6(4):422-428

Galis F, Ten Broek CMA, van Dongen S, Wijnaendts LCD (2010) Sexual dimorphism in the prenatal digit ratio (2D:4D). Arch Sex Behav 39:57-62

Gwunireama IU, Ihemelandu EC (2010) Geographical influence on digit ratio (2D: 4D): a case study of Andoni and Ikwerre ethnic groups in Niger Delta, Nigeria. J Appl Biosci 27:1736-1741

Hampson E, Sankar JS (2012) Re-examining the Manning hypothesis: androgen receptor polymorphism and the 2D: 4D digit ratio. Evol Hum Behav 33(5): 557-561

Jeevanandam S, Muthu PK (2016) 2D:4D ratio and its implications in medicine. J Clin Diagn Res 10(12):01-03

Kanchan T, Krishan K (2011) Anthropometry of hand in sex determination of dismembered remains - a review of literature. J Forensic Legal Med 18:14-17

Kanchan T, Krishan K, Sharma A, Menezes RG (2010) A study of correlation of hand and foot dimensions for personal identification in mass disasters. Forensic Sci Int 199:112.e1

Krishan K, Kanchan T, Asha N, Kaur S, Chatterjee PM, Singh B (2013) Estimation of sex from index and ring finger in a North Indian population. J Forensic Legal Med 20:471-479

Lippa RA (2003) Are 2D:4D finger-length ratios related to sexual orientation? Yes for men, no for women. J Pers Soc Psychol 85:179-188
Luxen MF, Buunk BP (2005) Second-to-fourth digit ratio related to verbal and numerical intelli-gence and the Big Five. Personal Individ Differ 39(5):959-966

Malas MA, Dogan S, Evcil EH, Desdicioglu K (2006) Fetal development of the hand, digits and digit ratio (2D:4D). Early Hum Dev 82:469-475

Manning JT (2008) The finger book: sex, behaviour and disease revealed in the fingers. Faber and Faber, London

Manning JT, Baron-Cohen S, Wheelwright S et al (2010) The 2nd to 4th digit ratio and autism. Dev Med Child Neurol 43:160-164

Manning JT, Kilduff LP, Trivers R (2013) Digit ratio (2D: 4D) in Klinefelter's syndrome. Andrology 1(1):94-99

Martel MM, Klump K, Nigg JT, Breedlove SM, Sisk CL (2009) Potential hormonal mechanisms of attention-deficit/hyperactivity disorder and major depressive disorder: a new perspective. Horm Behav 55(4):465-479

Mayhew TM, Gillam L, McDonald R, Ebling FJ (2007) Human 2D (index) and 4D (ring) digit lengths: their variation and relationships during the menstrual cycle. J Anat 211(5):630-638

Oyeyemi BF, Iyiola OA, Oyeyemi AW, Oricha KA, Anifowoshe AT, Alamukii NA (2014) Sexual dimorphism in ratio of second and fourth digits and its relationship with metabolic syndrome indices and cardiovascular risk factors. J Res Med Sci 19(3):234

Sen J, Kanchan T, Ghosh A, Mondal N, Krishan K (2014) Estimation of stature from lengths of index and ring fingers in a North-Eastern Indian population. J Forensic Legal Med 22:10-15

Setiya M, Jehan M, Godwin R, Sastya A (2017) Sexual dimorphism of digit ratio (2D:4D) in Madhya Pradesh. Int J Sci Stud 4(10):155-159

Tomulescu IM, Nicoras GL (2015) Comparative study of finger lengths and digit ratio in men of Ancona, Italy and Oradea, Romania. Studia Universitatis "Vasile Goldiş". Seria Ştiințele Vieții 25(3):151-155

Ventura T, Gomes MC, Pita A, Neto MT, Taylor A (2013) Digit ratio (2D:4D) in newborns: influences of prenatal testosterone and maternal environment. Early Hum Dev 89:107-112

Voracek M, Dressler SG, Loibl LM (2008) The contributions of Hans-Dieter Rösler: pioneer of digit ratio (2D:4D) research. Psychol Rep 103:899-916

Williams TJ, Pepitone ME, Christensen SE, Cooke BM, Huberman AD, Breedlove NJ et al (2000) Finger-length ratios and sexual orientation. Nature 404:455-456

Xu Y, Zheng Y (2015) The digit ratio (2D:4D) in China: a meta-analysis. Am J Hum Biol 27:304-309

\section{Submit your manuscript to a SpringerOpen ${ }^{\circ}$ journal and benefit from:}

- Convenient online submission

- Rigorous peer review

- Open access: articles freely available online

- High visibility within the field

- Retaining the copyright to your article

Submit your next manuscript at $>$ springeropen.com 